\title{
Fentanyl Citrate-containing Nasal Spray
}

National Cancer Institute

\section{Source}

National Cancer Institute. Fentanyl Citrate-containing Nasal Spray. NCI Thesaurus. Code C111760.

A nasal spray containing a phosphate-buffered solution of the citrate salt form of fentanyl, a short-acting, synthetic, lipophilic anilidopiperidine opioid, with analgesic activity. Upon applying one puff in the nostril, the fentanyl is rapidly absorbed through the nasal mucosa and selectively binds to and activates mu-opioid receptors in the central nervous system (CNS), mimicking the effects of endogenous opiates. Due to its quick onset and short duration of action, the administration of fentanyl nasal spray may relieve breakthrough pain in adults already receiving maintenance opioid therapy for chronic pain. 